\title{
GESTÃO DOS RECURSOS HÍDRICOS E DESENVOLVIMENTO SUSTENTÁVEL NA SUB-BACIA HIDROGRÁFICA ALTO CAMAQUÃ/RS
}

\author{
Simone Marfiga Degrandi ${ }^{(a)}$; Fernanda Maria Follmann ${ }^{(b)}$; Marilse Beatriz Losekann ${ }^{(c)}$ \\ (a) Departamento de Geociências/Universidade Federal de Santa Maria (UFSM), simone5z@ yahoo.com.br \\ (b) Departamento de Geociências/ Universidade Federal de Santa Maria (UFSM), ferfollmann@ yahoo.com.br \\ ${ }^{(c)}$ Departamento de Geociências/ Universidade Federal de Santa Maria (UFSM), marilosekann@ hotmail.com
}

\section{EIXO : BACIAS HIDROGRÁFICAS E RECURSOS HÍDRICOS: ANÁLISE, PLANEJAMENTO E GESTÃO}

\begin{abstract}
Resumo
O Alto Camaquã localizado na porção superior da Bacia Hidrográfica do Rio Camaquã (BHRC), possui como principais atividades econômicas a agropecuária e a mineração. $\mathrm{O}$ presente trabalho possui como objetivo apresentar as características da sub-bacia Alto Camaquã e os principais conflitos de usos dos recursos hídricos, discutindo a necessidade de políticas públicas para a gestão da água e conservação do patrimônio natural da sub-bacia. A metodologia utilizada para a realização do estudo assentou-se sobre a pesquisa documental e bibliográfica. Entre as discussões apresentadas, destaca-se que apesar da mineração ser considerada uma atividade econômica importante, atividades com uma maior ligação com a cultura local e com as características da paisagem, como a pecuária extensiva e o turismo de natureza, podem garantir um desenvolvimento territorial sustentável a médio e longo para a região.
\end{abstract}

Palavras-chave: Alto Camaquã; mineração; desenvolvimento sustentável; pecuária extensiva; turismo de natureza.

\section{Introdução}

A água é um recurso indispensável à vida e essencial aos processos de desenvolvimento econômico e social, podendo ser foco de conflito entre seus usuários (MOTTER, FOLETO, 2010). As políticas Federal e Estadual de Recursos Hídricos possuem um papel fundamental no estabelecimento dos instrumentos em relação a gestão e ao gerenciamento desse recurso. Entre os principais desafios a que se propõem essas políticas públicas, estão o de assegurar à atual e às futuras gerações a necessária disponibilidade de água em padrões de qualidade adequados aos respectivos usos, utilizando-a de forma racional e integrada, com vistas ao desenvolvimento sustentável (MOTTER, FOLETO, 2010).

Neste sentido, as políticas públicas de gestão ambiental e ordenamento territorial são essenciais ao desenvolvimento sustentável e a conservação dos recursos naturais das bacias hidrográficas. A gestão e o gerenciamento dos recursos hídricos têm como meta, compatibilizar a disponibilidade hídrica com os usos e demandas existentes.

No Rio Grande do Sul (RS), a gestão e o gerenciamento dos recursos hídricos é realizada através 
do Sistema Estadual de Recursos Hídricos (Lei 10.350/1994). Esta Lei estabeleceu a existência de três

Regiões Hidrográficas no RS: a região do rio Uruguai, que coincide com a Bacia Nacional do Uruguai; a região do Guaíba e a região do Litoral, que coincide com a Bacia Nacional do Atlântico Sudeste. As Regiões Hidrográficas foram subdivididas em bacias hidrográficas, totalizando 25 unidades, entre as quais se encontra a Bacia Hidrográfica do Rio Camaquã (BHRC), localizada na Região Centro-leste do RS, pertencendo à Região Hidrográfica Litorânea.

A BHRC foi dividida em seu Plano de Bacia em cinco Unidades de Planejamento e Gestão de Recursos Hídricos (UPGRH) ou sub-bacias: Alto Camaquã, Médio Camaquã, Baixo Camaquã-Duro, Arroio Velhaco e Arroio Turuçu. Dentre essas sub-bacias o Alto Camaquã é considerado pelo MMA (2000) como uma área de "extrema importância biológica" e "muito alta importância biológica" para a conservação da biodiversidade. Além disso, possui uma grande quantidade de afloramentos rochosos de grande beleza cênica e importância científica, que representam um patrimônio natural a ser conservado e protegido.

A partir desse contexto, o presente trabalho possui como objetivo apresentar as características da sub-bacia Alto Camaquã e os principais conflitos de usos dos recursos hídricos, discutindo a necessidade de políticas públicas para a gestão da água e conservação do patrimônio natural da sub-bacia. A metodologia utilizada para a realização do estudo se constituiu em uma pesquisa documental e bibliográfica, pois segundo Marconi e Lakatos (2010, p.48) "o levantamento de dados, primeiro passo de qualquer pesquisa científica, é feito de duas maneira: pesquisa documental (ou de fontes primárias) e pesquisa bibliográfica (ou de fontes secundárias)".

Assim, o trabalho apresenta inicialmente o enquadramento do sistema de gerenciamento da BHRC dentro da Política Nacional de Gerenciamento de Recursos Hídricos. Após, é apresentada uma caracterização geral da sub-bacia Alto Camaquã, embasada em informações obtidas junto ao site do Comitê de Gerenciamento da Bacia Hidrográfica do Rio Camaquã, dos relatórios do Plano de Bacia, entre outros trabalhos. O último tópico aborda a relevância da manutenção da pecuária extensiva, do turismo de natureza e da criação das Unidades de Conservação (UCs), como alternativas à conservação da paisagem e do patrimônio natural da sub-bacia.

\section{A Gestão dos Recursos Hídricos na Bacia Hidrográfica do Rio Camaquã (BHRC)}

No Brasil, um marco importante na legislação da gestão das águas é a Política Nacional de Gerenciamento dos Recursos Hídricos, instituída pela Lei Federal $n^{\circ}$ 9.433/97, que cria o Sistema Nacional de Gerenciamento de Recursos Hídricos (SINGERH). Entre os principais fundamentos da Lei $\mathrm{n}^{\circ}$ 9.433/97 fica estabelecido que a água é um recurso natural limitado, de domínio público e dotado de valor 
econômico; que a bacia hidrográfica é a unidade territorial para implementação da Política Nacional de Recursos Hídricos e atuação do Sistema Nacional de Gerenciamento de Recursos Hídricos e, que a gestão dos recursos hídricos deve ser descentralizada e contar com a participação do poder público, dos usuários e das comunidades (BRASIL, 1997).

No Rio Grande do Sul, a Lei 10.350/94, institui o Sistema Estadual de Recursos Hídricos (SERH) que é responsável pela gestão dos recursos hídricos com o apoio e articulação de diversas instituições estaduais, tais como o Conselho de Recursos Hídricos (CRH), o Departamento de Recursos Hídricos (DRH), os Comitês de Gerenciamento de Bacias Hidrográficas (CGBH), a Fundação Estadual de Proteção Ambiental Henrique Luiz Roessler (FEPAM) e as Agências de Regiões Hidrográficas (ARH) ${ }^{1}$.

Os Comitês de Gerenciamento de Bacias Hidrográficas estão na base do Sistema e representam a instância básica de participação da sociedade, com poder consultivo e deliberativo quanto à gestão das águas dentro da bacia hidrográfica. Para exercer sua função, os Comitês de Bacia são constituídos por representantes dos usuários de água na bacia (40\%), representantes da população da bacia (40\%) e representantes de órgãos públicos da administração direta estadual e federal ligados aos recursos hídricos (20\%) (MOTTER; FOLETO, 2010).

Cánepa et al (2001) definem os comitês como os "parlamentos das águas", nos quais se estabelece o ritmo de intervenções necessárias à conservação e desenvolvimento dos recursos hídricos, compatibilizando as metas e possibilidades de crescimento com os custos da preservação ambiental.

$\mathrm{Na}$ Bacia Hidrográfica do Rio Camaquã (BHRC) $)^{2}$, a exploração do ouro $(A u)$ e do cobre $(C u)$ e os impactos que causaram na sub-bacia Alto Camaquã foram uma das razões para criação do Consórcio Intermunicipal de Defesa do Rio Camaquã (CIDERCA) em 1991, dando origem ao atual Comitê de Gerenciamento da Bacia Hidrográfica do Rio Camaquã, criado em 1999.

Em 1989 ocorreu uma mortandade de peixes no Rio Camaquã devido à contaminação pelo mercúrio utilizado na mineração de ouro $(A u)$ em Lavras do Sul e cobre $(C u)$ em Caçapava do Sul. A partir disso, em dezembro do mesmo ano foi realizado um encontro para defesa do Rio Camaquã na Câmara de Vereadores de Encruzilhada do Sul, com a presença de representantes dos municípios, prefeitos, vereadores, deputados e população em geral, que resultou na criação de uma Comissão Executiva formada por Amaral Ferrador, Caçapava do Sul e Encruzilhada do Sul, para realizar os

\footnotetext{
${ }^{1}$ As Agências de Regiões Hidrográficas ainda não foram criadas no Rio Grande do Sul, sendo o DRH que subsidia tecnicamente o CRH que é responsável pela integração do Sistema Estadual de Recursos Hídricos (SERH).

${ }^{2}$ A BHRC é composta por 28 municípios que se encontram total ou parcialmente nela inseridos: Amaral Ferrador, Arambaré, Arroio do Padre, Bagé, Barão do Triunfo, Barra do Ribeiro, Caçapava do Sul, Cachoeira do Sul, Camaquã, Canguçu, Cerro Grande do Sul, Chuvisca, Cristal, Dom Feliciano, Dom Pedrito, Encruzilhada do Sul, Hulha Negra, Lavras do Sul, Pelotas, Pinheiro Machado, Piratini, Santana da Boa Vista, São Jerônimo, São Gabriel, São Lourenço do Sul, Sentinela do Sul, Tapes e Turuçu.
} 
primeiros trabalhos. Esta comissão conduziu as atividades até a institucionalização do CIDERCA (COMITÊ DE GERÊNCIAMENTO DA BACIA DO RIO CAMAQUÃ, 2017).

Em 1997 o CIDERCA foi designado pelo Conselho de Recursos Hídricos do RS para coordenar os preparativos da instalação do Comitê de Gerenciamento da Bacia Hidrográfica do Rio Camaquã. Desde então, iniciou-se um trabalho de conscientização e informação da população sobre a Lei Estadual n. ${ }^{\circ}$ 10.350/1994. A partir da instalação do comitê, efetivada em 1999, a gestão e o gerenciamento dos recursos hídricos tem sido realizada a partir de reuniões públicas trimensais e itinerantes, sediadas nos municípios da BHRC (COMITÊ DE GERÊNCIAMENTO DA BACIA DO RIO CAMAQUÃ, 2017).

A BHRC teve seu Plano de Bacia ${ }^{3}$ concluído pela GAMA Engenharia e Recursos Hídricos em 2016, financiado pelo Fundo de Investimento em Recursos Hídricos (FRH/RS) e coordenado pelo Departamento de Recursos Hídricos (DRH/SEMA/RS). Este plano, desenvolvido em conformidade com as Políticas Nacional e Estadual de Recursos Hídricos, visa fundamentar e orientar a implementação da Política Estadual de Recursos Hídricos no âmbito da BHRC e é neste processo de planejamento que devem ser projetados os interesses da população e dos usuários da bacia quanto aos usos qualiquantitativos das águas.

Conforme apresentado no Plano, a BHRC para fins de estudo e planejamento, pode ser regionalizada em cinco Sub-bacias ou Unidades de Planejamento e Gestão dos Recursos Hídrico (UPGRH): Baixo Camaquã-Duro, Médio Camaquã, Alto Camaquã, Arroio Velhaco e Arroio Turuçu (SEMA, 2016). Neste trabalho, será dada ênfase a sub-bacia Alto Camaquã devido à suas características ambientais, físicas e socioeconômicas singulares que serão descritas a seguir.

\section{A Sub-bacia Alto Camaquã}

A sub-bacia Alto Camaquã compreende a porção superior da Bacia Hidrográfica do Rio Camaquã (BHRC) (mapa 1), localizada no Centro-leste do RS, englobando parte dos municípios de Dom Pedrito, Lavras do Sul, Bagé, Caçapava do Sul, Santana da Boa Vista, Piratini, Pinheiro Machado e São Gabriel, totalizando uma área de 7.363,4 km² (IBGE, 2010; SEMA, 2016).

A população estimada da sub-bacia Alto Camaquã é de 92.365 habitantes, representando $26 \%$ do total da BHRC que é de 356.133 habitantes, constituindo a segunda maior população e a segunda maior taxa de urbanização $(81,45 \%)$ entre as demais sub-bacias (IBGE, 2010; SEMA, 2016).

\footnotetext{
${ }^{3}$ O Plano de Bacia Hidrográfica é um instrumento previsto na Políticas Nacional e Estadual, que visa a criação de elementos e meios que permitam aos Comitês, à sociedade e ao Estado o gerenciamento dos recursos hídricos superficiais e subterrâneos, de forma a garantir os usos múltiplos de forma racional e sustentável, garantindo água em quantidade e qualidade compatível com os usos pretendidos na bacia (MOTTER, FOLETO, 2010).
} 


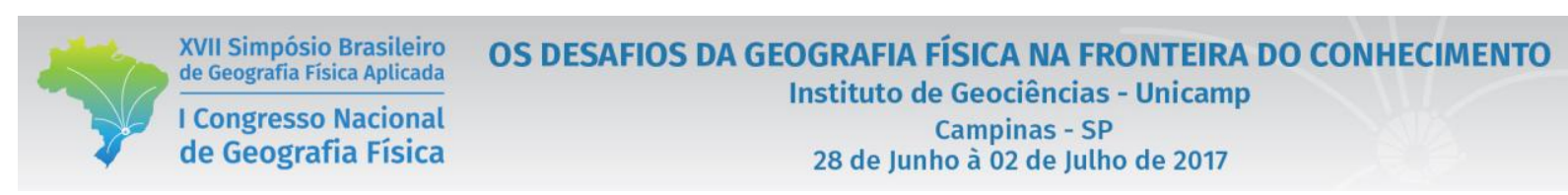

O Rio Camaquã é a principal drenagem que corta o domínio do Planalto Sul-Riograndense (Viero; Silva, 2010), tendo sua nascente oficial localizada na divisa entre os municípios de Lavras do Sul, Bagé e Caçapava do Sul, a partir da confluência do Arroio do Hilário com o Arroio Camaquã Chico, com desembocadura a Leste na Laguna dos Patos.

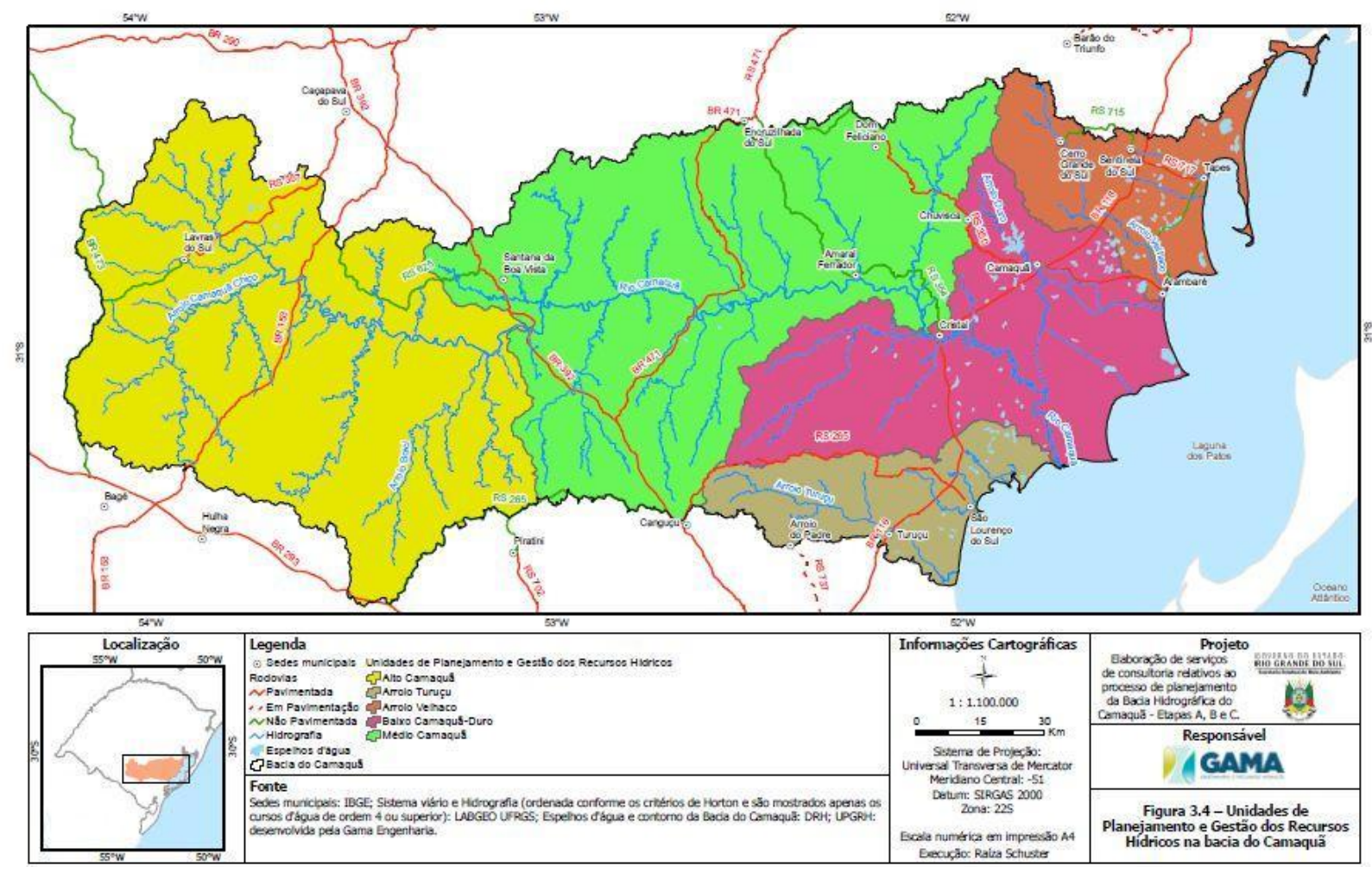

Mapa 1 - regionalização da Bacia Hidrográfica do Rio Camaquã (BHRC).

Fonte: SEMA (2016).

No Alto Camaquã, a configuração suave das planícies e coxilhas do Pampa gaúcho, dividem espaço com conjuntos de serras e morros que podem atingir até 600 metros de altitude em alguns pontos, justificando a denominação desta área como "Serras do Sudeste" do RS (DANTAS; VIERO e SILVA, 2010). Conforme destacam Dantas, Viero e Silva (2010) a área pode ser caracterizada pela presença de planaltos e serras baixas. Em relação aos solos destaca-se a dominância em 65,7\% da área da sub-bacia de Neossolos Litólicos, que são solos rasos e de regiões declivosas, conferindo grandes restrições ao desenvolvimento agrícola. Em relação às demais sub-bacias que compõem a BHRC, o Alto Camaquã é a que apresenta as maiores restrições de uso agrícola, apresentando apenas $41 \%$ da área apta para lavoura e 56,1\% da área com aptidão somente para pastagens (SEMA, 2016).

As formações vegetais do Alto Camaquã, característica do Bioma Pampa nessa região, compõem um mosaico campo-floresta, sendo apontada como uma área de "extrema importância biológica" e "muito alta importância biológica" para a conservação da biodiversidade, devido a existência de flora e fauna 
OS DESAFIOS DA GEOGRAFIA FÍSICA NA FRONTEIRA DO CONHECIMENTO

Instituto de Geociências - Unicamp

Campinas - SP

28 de Junho à 02 de Julho de 2017

ameaçadas de extinção (MMA, 2000; TRINDADE; BORBA; LEFBVRE, 2010). Esta região é também composta pelas formações florestais mais bem conservadas do Estado, que estão situadas nas encostas e nas faixas ciliares (TRINDADE; BORBA; LEFBVRE, 2010; SEMA, 2016).

As atividades econômicas se concentram na agropecuária e também na mineração. Na agricultura as lavouras temporárias predominam, com destaque para a produção de arroz no município de Dom Pedrito, que registrou em 2015 uma produção de 419.521 toneladas do produto (IBGE, 2015). A criação animal é significativa não só dentro do contexto estadual, mas entre as demais sub-bacias do Rio Camaquã, com destaque para o rebanho bovino (1.914.664) e ovino (928.098) que representam, respectivamente, cerca de $14 \%$ e $22 \%$ do efetivo de rebanho do Estado.

Quadro 1 - efetivos de rebanhos nas sub-bacias hidrográficas da BHRC

\begin{tabular}{|c|c|c|c|c|c|c|c|}
\hline UPGRH & Bovino & Equino & Bubalino & Suíno - total & Caprino & $\begin{array}{c}\text { Galináceos e } \\
\text { Codornas }\end{array}$ \\
\hline RS & 14.037 .367 & 535.299 & 69.731 & 6.320 .890 & 100.514 & 4.250 .932 & 149.751 .520 \\
\hline Bacia & 2.886 .637 & 143.641 & 15.209 & 168.681 & 41.122 & 1.242 .901 & 1.787 .568 \\
\hline Baixo Camaquã-Duro & 255.376 & 16.065 & 1.039 & 36.526 & 3.663 & 55.898 & 384.225 \\
\hline Médio Camaquã & 467.243 & 27.094 & 3.055 & 50.256 & 14.653 & 231.391 & 481.344 \\
\hline Alto Camaquã & 1.914 .664 & 80.165 & 9.056 & 36.020 & 18.432 & 928.098 & 360.388 \\
\hline Arroio Velhaco & 76.990 & 4.360 & 1.052 & 18.530 & 2.153 & 10.030 & 106.618 \\
\hline Arroio Turuçu & 172.364 & 15.957 & 1.007 & 27.349 & 2.221 & 17.484 & 454.993 \\
\hline
\end{tabular}

Fonte: SEMA (2016).

A mineração também constitui uma importante atividade econômica nessa região, especialmente a partir do final do século XVIII, quando movimentações de bandeirantes e garimpeiros levaram a descoberta de ouro no Arroio das Lavras em Lavras do Sul (TEIXEIRA, 1992). Alguns anos mais tarde, por volta de 1865 , ocorreu a descoberta do minério de cobre no distrito de Minas do Camaquã em Caçapava do Sul, por ingleses que garimpavam ouro em Lavras do Sul, dando início a atividade de mineração no município em 1870 (PAIM, 2002).

Desde a descoberta do cobre $(\mathrm{Cu})$ as Minas do Camaquã passaram por várias fases de exploração e pesquisa, intercaladas por períodos de paralisação total ou parcial da atividade de mineração (PAIM, 2002). Além de minérios metálicos, Caçapava do Sul desenvolve ainda a exploração de mármores a partir dos quais se obtém o calcário industrializado.

Em relação a qualidade das águas superficiais o Alto Camaquã está enquadrado na classe excelente (Classe 1) e boa (Classe 2), na maior parte das amostras estudadas (SEMA, 2016). Quanto aos usos da água na sub-bacia Alto Camaquã observa-se usos consuntivos e os não consuntivos ${ }^{4}$. Entre os usos

\footnotetext{
${ }^{4}$ Os usos consuntivos correspondem aos usos que implicam na retirada de água do manancial, reduzindo quantitativamente a disponibilidade para jusante, englobando o abastecimento humano, a dessedentação animal, o uso industrial e a irrigação. Já os usos não consuntivos correspondem aos usos que não promovem a retirada de água dos mananciais, mas apenas necessitam determinada disponibilidade hídrica para que ocorram, como geração de energia elétrica, pesca e navegação.
} 
consuntivos estão a irrigação, vinculada à produção de $\operatorname{arroz}\left(1,1 \mathrm{~m}^{3} / \mathrm{s}\right)$, que embora pouco expressiva em relação as demais sub-bacias, corresponde à maior demanda hídrica anual; a dessedentação animal (0,74 $\left.\mathrm{m}^{3} / \mathrm{s}\right) ;$ o abastecimento urbano/industrial $\left(0,02 \mathrm{~m}^{3} / \mathrm{s}\right)$ e o abastecimento industrial $\left(0,001 \mathrm{~m}^{3} / \mathrm{s}\right)$.

Conforme dados fornecidos pelo Plano de Bacia o enquadramento dos usos da água pretendidos, relativamente aos seus recursos hídricos superficiais na sub-bacia Alto Camaquã são, em ordem decrescente de indicação, o abastecimento para o consumo humano, a recreação e turismo, a dessedentação animal, a irrigação, a pesca e a preservação ambiental (SEMA, 2016).

\section{Recursos hídricos integrados à proteção do patrimônio natural no Alto Camaquã}

Entre as principais preocupações em relação a gestão dos recursos hídricos da sub-bacia Alto Camaquã estão a prevenção das poluições urbana e rural, causadas por esgotos não tratados, domésticos e animais e o controle da poluição originária da mineração (SEMA, 2016). Nesse sentido, serão discutidas algumas alternativas em relação a conservação das características naturais da paisagem da sub-bacia do Alto Camaquã, que suportam e mantém as vocações endógenas do território, ameaçadas especialmente pelos projetos de mineração que avançam sobre esse território.

Os dados contidos no Plano de Bacia da BHRC indicam que a sub-bacia Alto Camaquã apresenta o maior número de processos minerários, sendo os principais relacionados ao Cobre $(C u)$, Ouro $(A u)$, Zinco $(Z n)$, Calcário, Chumbo $(P b)$ e Granito. Caçapava do Sul é o município que possui o maior número de pedidos de Autorização de Pesquisa e Concessão de Lavra. Para Autorização de Pesquisa existem 48 para Cobre, 15 para Zinco, 15 para Ouro, 8 para Chumbo e 5 para Calcário. Já para Concessões de Lavra em Caçapava do Sul existem 10 processos para Calcário, 4 para Cobre, 1 para Água Mineral, 1 para Mármore e 1 para Talco (SEMA, 2016).

Atualmente a possível retomada da mineração nas Minas do Camaquã, constitui o processo que desperta maiores expectativas, tanto em relação a um possível crescimento econômico na região, quanto preocupações em relação a novos impactos ambientais e sociais que possam ser gerados, já que em 2016 a Votorantim Metais Hoding iniciou junto à FEPAM o processo de licenciamento ambiental para a Lavra de Minério Metálico de Zinco $(\mathrm{Zn})$, Cobre $(\mathrm{Cu})$ e Chumbo $(\mathrm{Pb})$ a céu aberto.

Conforme destaca o Plano de Bacia a lavra à céu aberto dos minérios mencionados pode ser altamente impactante para os recursos hídricos subterrâneos, pois o processo de lavra provoca a conexão do aquífero mais superficial com o(s) aquífero(s) mais profundo(s), causando a contaminação dos mesmos. Além da preocupação em relação à impactos ambientais, também os processos de estagnação econômica em relação ao encerramento das atividades, após o esgotamento das reservas de minérios economicamente viáveis, o desemprego e a migração das pessoas para outros locais, são problemas que 
XVII Simpósio Brasileiro de Geografia Fisica Aplicada

I Congresso Nacional

de Geografia Física
OS DESAFIOS DA GEOGRAFIA FÍSICA NA FRONTEIRA DO CONHECIMENTO

Instituto de Geociências - Unicamp

Campinas - SP

28 de Junho à 02 de Julho de 2017

despertam a preocupação da população que vive na bacia.

A partir do contexto apresentado, destaca-se que apesar da mineração ser considerada uma atividade econômica importante no Alto Camaquã, algumas atividades com uma maior ligação com a cultura local e com a conservação dos recursos naturais da sub-bacia, podem garantir um desenvolvimento territorial sustentável a médio e longo para a região. Entre essas atividades, destaca-se especialmente duas: a pecuária extensiva, desenvolvida sobre campos nativos, através de um manejo sustentável e o turismo de natureza.

A criação extensiva de gado é uma atividade econômica desenvolvida historicamente nessa região, que pode ser considerada um polo diferenciado devido à organização da produção com práticas adaptadas ao ambiente, que asseguram a reprodução social dos pecuaristas e ao mesmo tempo a conservação do Bioma Pampa (AZEVEDO; FIALHO, 2015). Devido a essa característica particular, o Alto Camaquã vem sendo foco de diversas ações e projetos voltados a pecuária familiar, que resultaram na criação da Associação para o Desenvolvimento Sustentável do Alto Camaquã (ADAC) em 2009. A ADAC constitui uma estrutura formal que reúne mais de 500 produtores de 8 municípios do Alto Camaquã, com foco especial na comercialização de carne ovina, artesanato em lã, mel, entre outros produtos caseiros (ALTO CAMAQUÃ, 2017).

Entre as estratégias adotadas pela ADAC está a vinculação entre produtos, território e pessoas, com a criação de uma marca coletiva, de modo que todos os produtos e serviços gerados possam usar este selo distintivo a fim de serem reconhecidos por uma identidade territorial comum. Assim, a marca Alto Camaquã (figura 1), tem como objetivo comunicar a identidade, a origem e o saber-fazer empregado no preparo de produtos típicos e da criação animal do território (ALTO CAMAQUÃ, 2017).
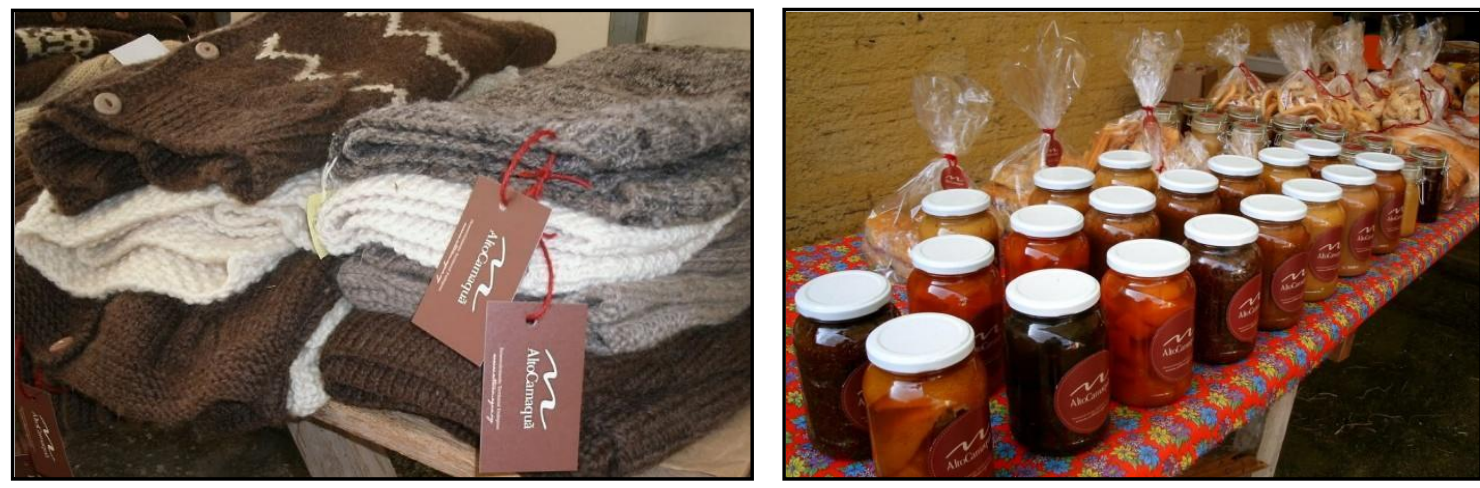

Figura 1: Artesanato em lã ovina e produtos caseiros diversos identificados com a marca Alto Camaquã. Fonte: ALTO CAMAQUÃ (2017). Disponível em: <http://www.altocamaqua.com.br/>.

A poluição de origem minerária, seja das minas desativadas, seja das que potencialmente poderão ser implantadas, pode nesse sentido, comprometer a diferenciação dos produtos e a imagem de um 


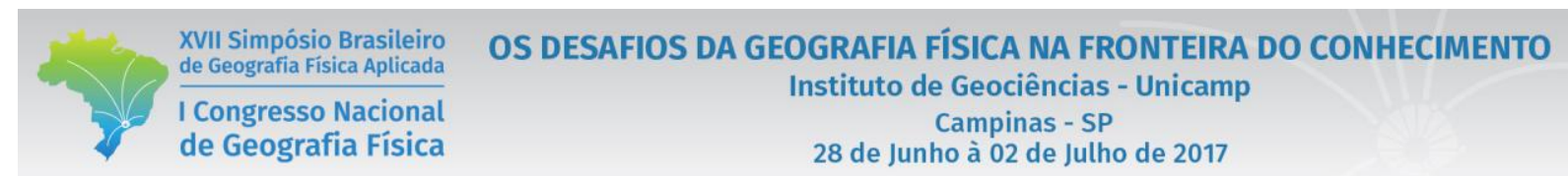

território que preserva os recursos naturais e ao mesmo tempo produz alimentos sadios e de qualidade (SEMA, 2016).

Uma outra alternativa ao desenvolvimento econômico da sub-bacia Alto Camaquã é o turismo de natureza, que constitui um segmento da atividade turística que utiliza, de forma sustentável, o patrimônio natural e cultural dos locais visitados (Mckerher, 2002) incentivando sua conservação ${ }^{5}$. Entre as potencialidades do Alto Camaquã possuem destaque os diversos conjuntos de afloramentos rochosos de significativa beleza cênica e importância cientifica dentro do Pampa, como por exemplo, a Serra do Segredo, as Guaritas e as Minas do Camaquã em Caçapava do Sul, o Rincão do Inferno e da Casa de Pedra no distrito de Palmas em Bagé, a Pedra Pintada em Santana da Boa Vista, o Paredão em Piratini, entre outros (figura 2).
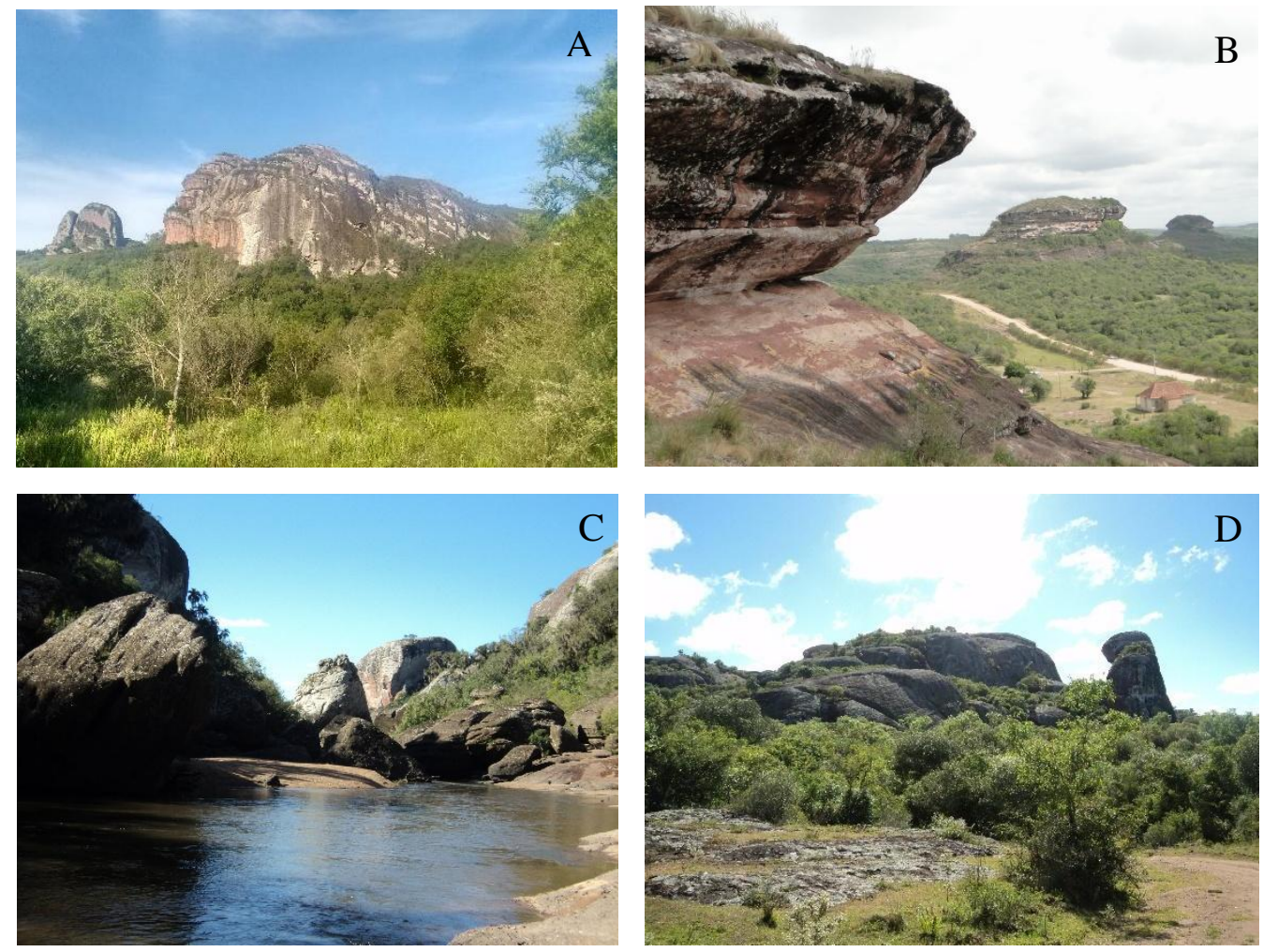

Figura 2: (A) Pedra do Segredo (Serra do Segredo, Caçapava do Sul); (B) Guaritas (Caçapava do Sul); (C) Rincão do Inferno (Rio Camaquã na divisa entre Lavras do Sul e Bagé) e (D) Casa de Pedra (Bagé).

Fonte: acervo particular Degrandi, S.M.

Além de constituírem locais de interesse para o desenvolvimento do turismo de natureza e de esportes de aventura, os afloramentos rochosos citados, devido a excelência didática das exposições

${ }^{5}$ De acordo com McKerher (2002), o turismo de natureza engloba ecoturismo, turismo de aventura, turismo educacional e uma profusão de outros tipos de experiências proporcionadas pelo turismo ao ar livre e alternativo. 
rochas, são geossítios ${ }^{6}$ visitados por excursões de estudantes de diversas instituições de ensino do Rio Grande do Sul e do restante do pais, para o ensino das geociências (BORBA, 2015).

O próprio Rio Camaquã constitui um excelente meio para a prática de atividades de educação ligadas ao turismo de natureza, já que desde 1995 é realizada a "Decida do Rio Camaquã", considerada uma iniciativa de cunho esportivo, turístico e ambiental, que busca valorizar e incentivar a conversação das características do Rio Camaquã e entorno.

Além da manutenção da pecuária extensiva como uma atividade econômica tradicional do território e do desenvolvimento do turismo de natureza, a criação de Unidades de Conservação (UCs) ${ }^{7}$ tais como as previstas pela Lei 9.985/2000, que cria o Sistema Nacional de Unidades de Conservação (SNUC), constitui uma medida importante para a conservação dos recursos hídricos e do patrimônio natural da sub-bacia Alto Camaquã. Apesar da singularidade, seja quanto aos aspectos ambientais bióticos ou abióticos de seu território, a sub-bacia Alto Camaquã, ainda não apresenta formas de proteção legal significativas que garantam a conservação de seu patrimônio natural. Sobre este aspecto o Ministério do Meio Ambiente (MMA, 2000) e o Zoneamento Ambiental do RS proposto pela FEPAM (FEPAM, 2007), recomendam a criação de UCs nesse território, considerando a baixa representatividade de UCs no Bioma Pampa. Entre as áreas mencionadas pelo MMA (2000) e FEPAM (2007) estão as Guaritas, a Serra do Segredo e o Rincão do Inferno.

A criação de UCs é de fundamental importância para a proteção do patrimônio natural, incluindo a conservação dos recursos hídricos. Um dos principais objetivos do SNUC é o de proteger e recuperar os recursos hídricos e edáficos do país. A manutenção e a recuperação qualitativa e quantitativa dos mananciais hídricos está fortemente condicionadas à tomada de consciência social quanto aos benefícios ambientais gerados por ecossistemas protegidos. O bem-estar social é inseparável da proteção e da recuperação das condições ecossistêmicas para a provisão de água de boa qualidade (MEDEIROS et al, 2011).

A criação de UCs no Alto Camaquã, somada à manutenção da pecuária extensiva e ao planejamento e ordenamento das iniciativas ligadas ao turismo de natureza, são alternativas de desenvolvimento territorial sustentáveis e que podem garantir a conservação dos recursos hídricos e dos demais patrimônios naturais frente aos avanços das atividades de mineração na sub-bacia.

\footnotetext{
${ }^{6}$ Pontos de interesse geológico-geomorfológico que possuem destacado valor científico, educativo, cultural e/ou turístico em uma determinada paisagem.

7 De acordo com a definição apresentada pela Lei 9.985/2000 uma Unidade de Conservação (UC) é o espaço territorial e seus recursos ambientais, incluindo as águas jurisdicionais, com características naturais relevantes, legalmente instituído pelo Poder Público, com objetivos de conservação e limites definidos, sob regime especial de administração, ao qual se aplicam garantias adequadas de proteção (BRASIL, 2000).
} 


\section{Considerações Finais}

Contemporaneamente, um dos principais desafios ambientais é realizar uma gestão e gerenciamento dos recursos hídricos de maneira eficaz, para que se possa atender a uma sociedade que possui demandas cada vez maiores em relação a este recurso, sem que este perca suas características qualiquantitativas (MOTTER; FOLETO, 2010). Nesse sentido, necessita-se discutir alternativas que possam propiciar a melhoria da qualidade e quantidade de água no espaço, possibilitando ao meio desempenhar suas funções de proteção a este recurso natural.

Dessa forma, para a gestão e conservação dos recursos hídricos e do patrimônio natural biótico e abiótico da sub-bacia hidrográfica Alto Camaquã, deverão ser adotadas alternativas de desenvolvimento territorial que estejam de acordo com as características ambientais, físicas e culturais do território, tais como a pecuária extensiva, desenvolvida sobre campos nativos e o turismo de natureza. Além disso, destaca-se o importante papel do Comitê de bacia e da população local no que se refere ao ordenamento territorial da BHRC e em relação ao gerenciamento dos recursos hídricos da sub-bacia do Alto Camaquã, pois a extração de minérios compromete não apenas a qualidade das águas, mas também, as estratégias de desenvolvimento territorial sustentáveis que estão em curso atualmente.

\section{BIBLIOGRAFIA}

AZEVEDO, L. F. FIALHO, M. A. V. "Florestamento" no Pampa Brasileiro: a visão dos pecuaristas familiares do Território do Alto Camaquã/RS. Desenvolvimento e Meio Ambiente, v. 33, p. 209-224, abr. 2015. Disponível em: <http://revistas.ufpr.br/made/article/view/35984/25145>. Acesso em: 02 fevereiro de 2017.

BORBA, A. W. Proposta de uma (Geo)identidade Visual para Caçapava do Sul, "Capital Gaúcha da Geodiversidade". Geographia Meridionalis. v. 01, n. 02, p. 405-411, Jul./Dez. 2015. Disponível em: <https://periodicos.ufpel.edu.br/ojs2/index.php/Geographis/article/view/6981/4927>. Acesso em: 02 de fevereiro de 2017.

BRASIL. Lei 10.350, de 30 de dezembro de 1994. Institui o Sistema Estadual de Recursos Hídricos. Disponível em <http://www.hidro.ufcg.edu.br/twiki/pub/ASUB0/LegislacaoAsub/RioGrandedoSuln10.350.pdf >. Acesso em: 01 de fevereiro de 2017.

BRASIL. Lei no 9.433, de 8 de janeiro de 1997. Institui a Política Nacional de Recursos Hídricos. Disponível em:< http://www.planalto.gov.br/ccivil_03/leis/L9433.htm>. Acesso em: 03 de fevereiro de 2017.

BRASIL. Lei ${ }^{\circ}$ 9.985, de 18 de julho de 2000. Institui o Sistema Nacional de Unidades de Conservação. Disponível em: 〈http://www.mma.gov.br/images/arquivos/areas_protegidas/snuc/Livro\%20SNUC\%20PNAP.pdf >. Acesso em: 06 de fevereiro de 2017.

CÁNEPA, E. M.; ZORZI, I.; GRASSI, L. A. T.; NETO, P. S. Os comitês de Bacia no Rio Grande do Sul: Formação, dinâmica de funcionamento e perspectivas. Taquari - Antas (Comitê de Gerenciamento da Bacia Hidrográfica) nov./2001. 
COMITÊ DE GERENCIAMENTO DA BACIA HIDROGRÁFICA DO RIO CAMAQUÃ. Disponível em:< http://www.comitecamaqua.com/index.php/ocomite/historico>. Acesso em: 06 de janeiro de 2017.

DANTAS, M. E; VIERO, A. C.; SILVA, D. R. A. Origem das Paisagens. In: VIERO, A. C.; SILVA, D. A. R. (Org.). Geodiversidade do Estado do Rio Grande do Sul. Porto Alegre: CPRM, p.35-50, 2010. Disponível em: <https://sh16novas.wordpress.com/2012/07/12/geodiversidade-do-rio-grande-do-sul-livro-e-mapa-para-download/>. Acesso em: fevereiro de 2017.

MARCONI, M. A.; LAKATOS, E. M. Fundamentos de metodologia científica. 5 ed. São Paulo: Atlas, 2003.

MCKERHER, B. Turismo de Natureza: Planejamento e Sustentabilidade. 2002. Contexto.

MEDEIROS, R. et al. Contribuição das unidades de conservação brasileiras para a economia nacional: Sumário Executivo. Brasília: UNEP-WCMC, 2011.

MINISTÉRIO DO MEIO AMBIENTE. Avaliação e ações prioritárias para a conservação da biodiversidade da Mata Atlântica e Campos Sulinos/por: Conservation International do Brasil, Fundação SOS Mata Atlântica, Fundação Biodiversitas, Instituto de Pesquisas Ecológicas, Secretaria do Meio Ambiente do Estado de São Paulo, SEMAD/Instituto Estadual de Florestas-MG. Brasília: MMA/SBF, 2000. Disponível em: <http://www.rbma.org.br/anuario/mata_04_areas_prioritarias.asp>. Acesso em: fevereiro de 2017.

MOTTER, A. F. C.; FOLETO, E. M. Um olhar sobre a gestão dos recursos hídricos: o caso do Comitê de Gerenciamento da Bacia Hidrográfica dos Rios Santa Rosa, Santo Cristo e Turvo - Noroeste do Rio Grande do Sul. Perspectiva. Erechim. v.34, n.126, p. 143-155, junho/2010.

PAIM, P. S. G. Minas do Camaquã, RS - Marco da história da mineração de cobre no Brasil. In: Schobbenhaus,C.; Campos,D.A.; Queiroz,E.T.; Winge,M.; Berbert-Born,M.L.C. (Edits.) Sítios Geológicos e Paleontológicos do Brasil. $1^{a}$ Ed, Brasília: DNPM/CPRM - Comissão Brasileira de Sítios Geológicos e Paleobiológicos (SIGEP), 2002, v.01, p. 501-510. Disponível em: 〈http://www.unb.br/ig/sigep/sitio064/sitio064.pdf>. Acesso em: 01 de fevereiro de 2017.

TEIXEIRA, E. Lavras do Sul: na Batéia do Tempo.Lavras do Sul: [s.n], 1992.

TRINDADE, J. P. P.; BORBA, M. F.S.; LEFEVBRE, J. Território do Alto Camaquã: apresentação da cobertura vegetal do Alto Camaquã. Bagé: Embrapa Pecuária Sul, 2007. 